(Paper No. 3088.)

\title{
"The Erection of a Steel Viaduct upon the Highland Railway."
}

By Henry Thomas White, Assoc. M. Inst. C.E.

IN the design of steel girder-bridges, viaducts, and roofs, as well as in their construction, it is most important to keep distinctly in view the process by which the structure is ultimately to be erected; for the actual work of erecting such framed structures will often be attended with considerable difficulties, demanding as much attention from the engineer as any other matters involved in the general problem of bridge-construction.

The method that may be chosen for the erection of any structure will depend entirely upon its situation and upon the various facilities for getting the material to the site. It may be that one or other of the ordinary processes will be eligible; otherwise, as not infrequently occurs, some special arrangements must be devised to meet the exigencies of a particular case. When the method of erection has been decided upon, it must be carefully considered, whether it does not involve some special arrangement of parts in the general design of the structure; and it will also determine how far the structure may be riveted together in the maker's yard, and what must be left to be done at the site. The Author is of opinion that a fuller acquaintance on the part of the designer with the peculiar facilities or difficulties attaching to the site of the structure upon which he is engaged, and the method of erection, which is determined thereby, would frequently save unnecessary labour and would conduce to better construction.

In the present Paper, as a contribution to the subject, the Author proposes to give a description of the method which was successfully employed upon the erection of a viaduct upon the Highland Railway in a situation that called for the employment of special appliances.

The viaduct forms part of the new direct line from Aviemore to Inverness, and carries the railway across the valley of the 
River Findhorn in nine spans of 130 feet each, measured between the centres of the piers. The steel superstructure of each span consists of a pair of independent girders of uniform depth, placed 16 feet apart from centre to centre, and carrying the railway upon an upper deck, by means of cross-girders attached to the upper booms. The main girders are supported upon piers of granite masonry, whose height varies with the contour of the valley, the highest being 118 feet from ground-level to the bearings of the girders. The viaduct is built upon a curve of 40 chains radius, and upon a gradient of 1 in 60 .

For various reasons it was not considered practicable in this case to erect the superstructure either by lifting the girders from the ground, or by the alternate plan of launching them across the piers from the embankment at each end, as either plan would be attended with great difficulties, and therefore some other scheme was necessary. The method that was devised was that of providing a long bridge-like structure, or travelling stage, composed of steel and timber, which was put together upon the approach-embankment at one end of the viaduct, and was then pushed across the viaduct span after span, the girders of each span being built upon it and left in their final positions, when the stage travelled forward to the next span. The total length of this travelling-stage was 193 feet, measured on the bottom boom, and it consisted of two main trusses, 18 feet deep, braced together at the top and bottom by timber transoms and steel rods. The main trusses, Fig. 1, were of a simple type, and were made of a skeleton of steel bars. These bars are flitched on each side with timber in every member, which, under any condition, can act as a strut, while the

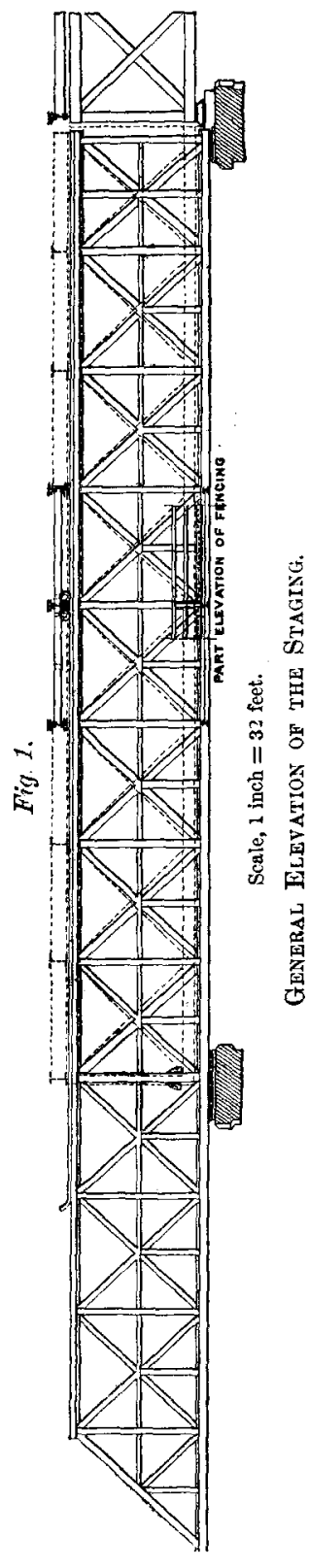


verticals, which can only act as struts, are wholly of timber and have no steel bar. At the bottom of each vertical, folding-wedges were provided, so that the vertical could be tightened to take out any permanent deflection of the stage. On each side of the steel bar, in the bottom booms, an angle-bar was riveted, which, besides supplying a sufficient area of metal to take up the tension in the boom, acted as a path upon which the stage was rolled forward.

The steel skeleton was riveted together, and the timber was carefully fitted on to it, recesses being cut in the timber to receive the rivet-heads. The timber, which varied in section from 12 inches by 12 inches, and 10 inches by 10 inches in the booms to 12 inches by 6 inches and 10 inches by 4 inches in the vertical struts, was bolted to the steel skeleton with bolts passing through both timbers. The small intermediate struts, shown in Fig. 1, do not form part of the web-system of the truss, but were placed there merely to strengthen the bottom boom, when it had to act as a beam as the stage travelled over the rollers on which it moved. The main trusses of the stage were placed 9 feet apart, from centre to centre, and were connected at the top and bottom by horizontal systems of bracings, consisting of timber transoms framed across between the trusses at the head and foot of each vertical, and diagonal steel rods with screw connections; while the stage was further stiffened by bracing in the transverse plane, consisting of diagonal rods applied at each vertical of the truss, as shown in Fig. 2, and provided with adjustable screw couplings. Being thus braced in every direction, the stage was exceedingly rigid, which was very necessary, as it had to withstand, besides its vertical loads, a very strong lateral wind-pressure. At the back end, and again at a point 130 feet from that end, that is, the bearing point on the next pier, the stage was stiffened with diagonal struts, and special beams were fixed across it horizontally, by which it could be lifted by means of hydraulic jacks whenerer it was necessary to insert or remove the rollers from underneath it. The main body of the stage, constructed as above described, was capable of travelling forward telescopically between the erected steel girders of any one span, so as to form a temporary bridge across the next opening; but, before commencing the erection of a pair of girders, the stage was extended laterally by attaching to it, on each side, a movable platform, as shown in Fig. 2.

Rolled-steel joists ( 6 inches by 3 inches in section), projecting from the stage on each side opposite each vertical, were attached to: the lower boom by straps, which passed through and took a 
Proceedings.] WHITE ON THE ERECTION OF A STEEL VIADUOT. 201

bearing upon a steel plate, bolted to the outside of the lower boom of the stage. The joists were held in place by a pin passing through the strap at the back of the plate, and were supported by a 11-inch diameter chain, fastened to the upper boom of the truss by a strap-bolt passing through it, and attached to the joist by links and a pin. In each chain was a strong union-screw, by means of which the joist could be levelled when in position. The joists, which were 16 feet apart, were connected by light rods attached to their centres, which served to keep them parallel and

Fig. 2.

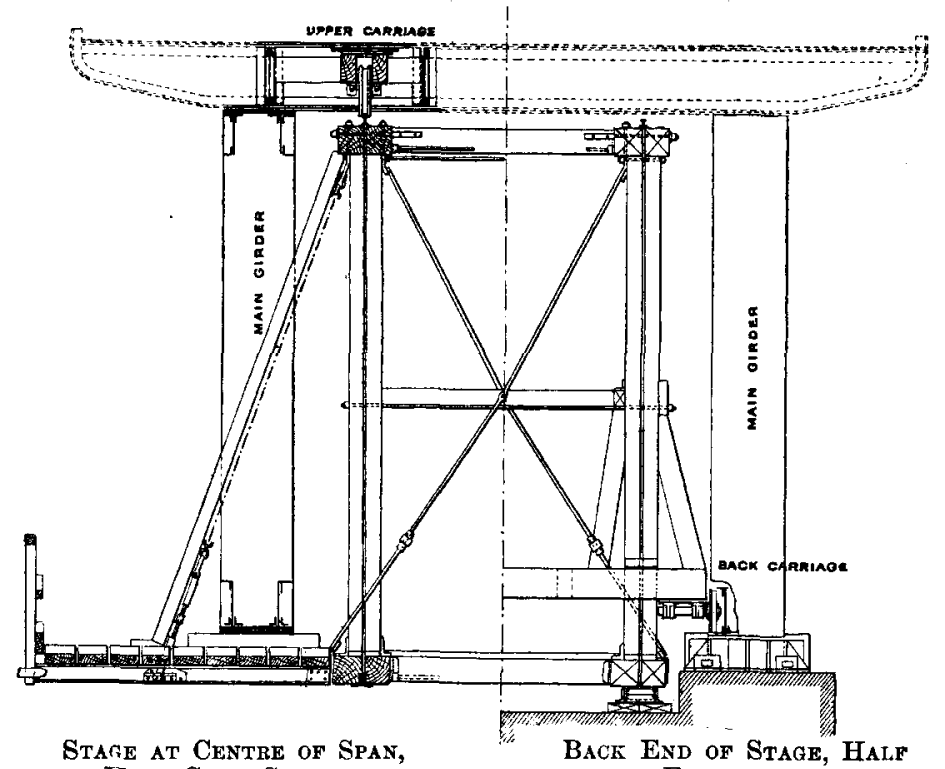

Half Cross Section.

ELEVATTON.

Scale, $\frac{2}{3}$ inch $=1$ foot.

square with the stage, the last joist at each end being braced to the bottom boom of the stage by a chain and union-screw. On the joists were placed planks 4 inches thick, and on the outside was a strong hand-rail, supported by posts which were fitted into sockets at the ends of the joists. This formed a good and secure platform and on this the girders were built.

The materials were brought to the work upon the earthen embankment which formed the approach to one end of the viaduct, and upon this embankment the travelling stage had to be put together. The steel skeleton of each truss was built and riveted 
lying upon its flat, and then the timber was bolted on. When this was finished, the completed truss was turned up on edge, by means of five derricks attached to it at intervals along the top boom. The second truss was treated similarly, and after the cross and diagonal bracing had been put in, the stage was ready for launching.

For launching the stage, rollers were put under each truss in two places. These rollers were 4 inches in diameter, and were made in sets of eight, fixed in a steel frame; two sets, that is, sixteen rollers, were placed end to end, affording a bearing 9 feet in length at each of the four points of support. The rollers were set in their frames to the gradient of 1 in 60 , in order that the frames could be bedded level.

The clear span between the piers was 120 feet, and the length of the stage was 193 feet, so that when the stage was pushed forward from the abutment across the first span there would be 73 feet of the stage on the bank to serve as a counterbalancing arm at the moment when the forward point of the stage was just landing on the first pier. It should have been mentioned that the first 130 feet of the stage was made without any camber at all, but the 63 feet at the point had 6 inches of camber, to compensate for the deflection which would occur when the whole 120 feet between the jiers was overhanging without support. When the building of the stage was completed and the rollers were put under it, the rear end was loaded with about 40 tons of kentledge to prevent the forward end from overbalancing, and the whole was launched forward by means of hand-winches and block-tackle till the forward end was over the first pier. This end was then temporarily packed up off the pier (the end of the stage arrived usually about 1 foot 6 inches above the pier), and then the rollers, which had been used at the rear end, were taken across and were fixed under the point on the first pier. The launching was then continued till the back 130 feet length of the stage bridged the first span of the viaduct and the forward 63 feet was overhanging into the second span. This was the final position of the stage for the building of the first span of the viaduct. The weight of the stage, when stripped of its side platforms and all encumbrances, was about 84 tons, which, with the 40 tons of kentledge, made a total load of 124 tons, which had to be moved across the first span.

The stage being in position across the span, it was lifted at each end and flat plates were inserted between the rollers and the angle bars which formed the roller-path on the stage, in order to prevent abrasion of the rollers. The platforms were then 
fixed on each side of the stage to receive the steelwork of the girders.

For building the girders a hand-crane was provided, which travelled upon rails on the top of the stage. The lower booms were first laid down upon slack-blocks lying upon the planking of the side platforms, and then the remaining members of the girders were built in the ordinary way. This part of the work calls for no especial remark, except that two points had to be noted : firstly, a considexable excess of camber had to be put in the bottom booms when first laid down, in order to allow for the ever-increasing deflection of the stage as weight was added to it; thus, although $1 \frac{1}{2}$ inch was the camber specified for the girders when finished and under full permanent load, it was found necessary to put in $3 \frac{1}{2}$ inches when first laying the booms down. The second point to be observed was that the stage had to be loaded as equally as possible upon each side-platform; that is to say, that as soon as one member had been fixed on one side, the corresponding member was fixed upon the opposite side. The total weight of each girder was 45 tons. The maximum deflection noted in the stage was about 2 inches, and a large part of this remained after the weight of the girders had been taken off. It was, however, always found possible to get rid of this permanent deflection by tightening the wedges under the vertical struts of the stage.

As soon as the cross-girders and rail-bearers had been fixed upon the main girders, the side-platforms of the travelling stage were removed and stacked upon the cross-girders, and preparations were then made for moving the stage to the next span. This operation required much care, on account of the great length and weight of the stage and the slenderness of the tall piers over which it had to travel. Before the commencement of the movement the stage was between the girders of the bridge, and was resting on rollers on the two piers, 130 feet apart, while the remaining length of 63 feet overhung into the next span forwards. At the back end of the stage, which was specially stiffened, a wheel and axle were now fixed in bearings upon each side, at such a height as to run upon the inside flanges of the bottom booms of the girders. As there were rivet-heads along these flanges, steel strips, of the thickness of the heads and perforated to receive them, were fixed upon them, and thus a smooth path was provided for the wheels to run upon. At the beginning of the movement the weight upon these two wheels was approximately 30 tons, but it is obvious that the load on the trailing wheels was gradually 
reduced by the forward motion of the stage; and, when the centre of gravity arrived at the roller frame upon the pier, no further support was needed at the rear end. To allow of the further movement of the stage without tipping, a pair of flanged guide-wheels was mounted over each truss of the stage, running in bearings which were attached to timber framing on each side of the central cross-girder, so that the whole weight of the span last erected was called into play as a counterbalance. The guide-wheels were mounted immediately over the rails, which have before been mentioned as forming a road for the travelling hand-crane, and which bore against the guide-wheels, as the stage travelled forwards. The motive power for moving the stage was obtained by block-tackle worked by hand-winches; a set of blocks was fixed on each side, one block being fixed to the bottom boom of the girder at its forward end, and the other block being made fast to the bottom boom of the stage; the leading parts of the falls being taken directly, or, when necessary, through snatchblocks, to the winches, which stood on the cross-girders on the top of the bridge. It has been roughly calculated that the tractive force necessary to move the stage forward was about 13 tons.

As soon as the point of the stage reached the next pier, men were sent across and the point was temporarily packed up, and then the rollers which had been left behind on the backward pier were taken across and were fixed under the point. The point was now eased up with jacks and the wheels were removed from between the cross-girders at the back end of the stage, and then the point was lowered on to the rollers just fixed. The stage was now again resting upon rollers upon two piers, and the movement was continued forwards for the remaining 60 feet, until the stage occupied the right position (in point of distance) for building the girders of the next span upon it. Owing; however, to the viaduct being built upon a curve, the stage had now to be moved sideways upon the forward pier. For this purpose the stage was lifted again by four hydraulic jacks, the rollers were removed and were replaced by a planed bridge-rail bolted to a timber which was laid upon the pier transversely under the stage. When resting on this rail, which was well greased, it was comparatively easy to move the stage sideways by means of jacks, aided by union-screws attached to the holding-down bolts which were built into the pier. As soon as the forward end had been moved to the centre of the pier it was again lifted, the rail was removed, and the rollers replaced ready for the next move forwards. 
Proceedings.] WHITE ON THE ERECTION OF A STEEl VIADUOT. 205

The side platforms were then fixed and the stage was ready to receive the girders of another span.

When the stage was moved forward in fairly calm weather, it was not difficult to keep it travelling in a straight line upon its rollers. On the other hand, it was impossible to move it during a strong side wind, owing to the large surface offered by the stage, and the leverage at which the wind-pressure acted when a large length of the stage was overhanging without support. A distinct vibration was felt in the piers during the moving of the stage.

In conclusion, it may be remarked that the appliances which have here been described were perfectly successful in the accomplishment of the work for which they were designed; and the method of erection was found to be convenient, expeditious and well adapted to the situation.

The Paper was accompanied by two tracings from which the Figures in the text have been prepared. 